\title{
IDENTIFIKASI KEKERINGAN HIDROLOGI DI DAS CITARUM HULU
}

\author{
Nyayu Fatimah Zahroh ${ }^{1}$ dan Sara Aisyah Syafira ${ }^{1}$ \\ ${ }^{1}$ Staf Bidang Pengkajian dan Penerapan Teknologi Pembuatan Hujan, UPT-Hujan Buatan, \\ BPPT Gedung 1lt. 19, Jl. MH Thamrin no. 8 Jakarta. Telp. (021) 3168816 - 32 Fax. (021) \\ 3906225
}

\begin{abstract}
Intisari
DAS Citarum Hulu merupakan salah satu subdas yang paling berpengaruh di DAS Citarum dengan Waduk Sagulingnya. Besarnya debit yang masuk ke waduk menjadi sangat penting demi keberlangsungan kinerja waduk tersebut, misalnya untuk pembangkit listrik. Penelitian ini bertujuan untuk mengetahui karakteristik kekeringan hidrologi, relasinya dengan curah hujan, dan analisis frekuensi kejadian kekeringan hidrologi di DAS Citarum Hulu. Data dari pos duga air Nanjung digunakan dalam menentukan ambang batas kekeringan hidrologi yang kemudian diperoleh karakteristik kekeringan hidrologi. Hasil menunjukan bahwa rata-rata periode kekeringan di DAS Citarum Hulu terjadi mulai dari bulan Juni hingga Oktober. Terdapat keterlambatan antara waktu curah hujan turun dan waktu ketika debit naik akibat input dari curah hujan. Hasil analisis frekuensi menunjukan bahwa kekeringan maksimum yang terjadi pada tahun 1994 memiliki periode ulang 52 tahun dan kekeringan sering terjadi dengan durasi kurang dari 20 hari.
\end{abstract}

Kata Kunci: Kekeringan Hidrologi, Volume Defisit, FDC, Curah Hujan, Durasi

\begin{abstract}
Citarum Hulu is one of the most influential Citarum sub-basin with the Saguling Reservoir. The amount of discharge into the reservoir is very important for the sustainability of the reservoir's performance for power plants in example. This study aims to determine the characteristics of hydrological drought, its relationship with precipitation, and frequency analysis of hydrological drought occurrence in Citarum Hulu. Data from Nanjung post are used in determining the threshold of hydrological drought which then acquired the characteristics of hydrological drought. The results showed that the average period of drought in Citarum Hulu occurred from June to October. There is a lag between the time when rainfall drops and the time when the discharge rise due to the input of rainfall. Frequency analysis results showed that the maximum drought that occurred in 1994 had a 52-year return period and drought often occurs with a duration of less than 20 days.
\end{abstract}

Keywords: Hydrological drought, Volume deficit, FDC, precipitation, duration

\section{PENDAHULUAN}

Salah satu Daerah Aliran Sungai (DAS) yang memiliki peranan penting bagi wilayah sekitarnya terutama dalam hal pembangkit listrik yaitu DAS Citarum, yang merupakan DAS terbesar di Jawa Barat. Luas DAS ini yaitu sekitar $6614 \mathrm{~km}^{2}$ sedangkan panjang sungainya yaitu $269 \mathrm{~km}$. Terdapat tiga waduk besar yang berada di DAS Citarum yaitu Saguling, Cirata, dan Jatiluhur. Ketiga waduk tersebut menghasilkan daya listrik 5 milyar kwh/tahun atau setara dengan 16 juta ton BBM/tahun (Cahyaningsih 2010).
Untuk dapat tetap berfungsi sebagaimana mestinya, kecukupan air di DAS Citarum ini menjadi hal yang penting dan kekeringan merupakan suatu fenomena alam yang dapat mengganggu dalam hal ini. Dalam Tallaksen dan Van Lanen (2004), kekeringan didefinisikan sebagai suatu kejadian luas yang berkelanjutan dan regional yang mana ketersediaan air alam berada di bawah rata-rata. Tipe kekeringan kemudian dapat dibedakan dari defisit air yang mempengaruhi tahapan hidrologi, yaitu kekeringan meteorologi, kekeringan kelembaban tanah atau pertanian, dan kekeringan hidrologi (Tallaksen dan Van Lanen 2004, Fleig 2004). 
Kekeringan hidrologi merupakan tipe kekeringan yang sudah berada pada tahap yang paling dekat keterkaitan atau pengaruhnya terhadap fungsi DAS Citarum sebagai pembangkit listrik. Oleh karena itu, kajian karakteristik kekeringan hidrologi menjadi hal yang penting dan bermanfaat, seperti yang dituliskan oleh Zelenhasic (2002), yaitu untuk mencegah kerusakan pada kondisi kekeringan dan mengetahui kondisi-kondisi abnormal seperti pada saat kondisi kekeringan hidrologi agar reservoir di wilayah kajian dapat bekerja saat kondisi tersebut.

Salah satu faktor yang dapat mempengaruhi ketersediaan air disuatu DAS seperti yang dituliskan oleh Marganingrum et al (2013) yaitu curah hujan sebagai input utama suatu DAS. Lebih lanjut dituliskan pula olehnya bahwa curah hujan variabel acak dan hujan yang berkarakter acak akan menjadi debit aliran yang bersifat acak pula, serta instrumen statistik dapat digunakan untuk mengetahui perilakunya. Dituliskan pula bahwa apabila curah hujan yang jatuh ke permukaan bumi dengan pola penggunaan lahan yang tetap (fix variable) maka debit aliran akan mengikuti pola curah hujan.

Penelitian kali ini bertujuan melakukan kajian karakteristik kekeringan hidrologi di DAS Citarum Hulu, mempelajari keterkaitannya dengan curah hujan yang terjadi dalam suatu periode tertentu, serta menganalisis frekuensi kejadian kekeringan yang teridentifikasi pada periode data yang tersedia.

\section{METODE}

Data yang digunakan dalam penelitian ini adalah data debit dari pos duga air Nanjung, Citarum (06 $57^{\prime} 00^{\prime \prime}$ LS dan 107 $17^{\circ}$ '00"BT) periode tahun 1918-1935 dan 1973-2010 yang diperoleh dari Puslitbang Air, Bandung dan data curah hujan wilayah tahun 1999-2001, 20052008 dari stasiun klimatologi Cisomang (06 $54^{\prime} 49^{\prime \prime}$ LS dan $107^{\circ} 38^{\prime} 40^{\prime \prime}$ BT), Cicalengka (06 $59^{\circ} 16^{\prime \prime}$ LS dan 107 $50^{\circ} 31^{\prime \prime}$ BT) dan Cisondari $\left(07^{\circ} 05^{\prime} 34^{\prime \prime}\right.$ LS dan $107^{\circ} 28^{\prime} 46^{\prime \prime}$ BT). Data debit tersebut kemudian diolah menggunakan metode ambang batas tetap (fixed threshold) untuk penentuan ambang batas kekeringan, kemudian digunakan untuk menentukan karakteristik kekeringan hidrologi. Prosedur pengolahan data meliputi flow duration curve (FDC), penentuan durasi dan volume defisit kekeringan hidrologi, dan analisis frekuensi. Kemudian hasil analisis dibandingkan dengan data curah hujan agar dapat diketahui respon dari debit terhadap kejadian hujan.

\section{Flow Duration Curve}

Flow duration curve (FDC) merupakan grafik hubungan antara debit dan frekuensi terlampaui, dengan mengurutkan data complete duration series atau data harian dari terbesar sampai terkecil sehingga diperoleh frekuensi terlampaui pada setiap nilai (WMO 2008). Menurut Searcy (1959), kurva durasi aliran (flowduration curve) merupakan kurva frekuensi kumulatif yang menunjukkan persen waktu dimana suatu debit dapat melampaui atau menyamai periode yang digunakan. Data yang digunakan dalam perhitungan FDC tidak selalu data harian tetapi bisa menggunakan data mingguan ataupun bulanan.

Tipe sungai Sungai Ciujung, Brantas, dan Bengawan Solo adalah tipe sungai perennial, aliran sungai mengalir sepanjang tahun. Metode grafis FDC ini sangat baik dan sering diaplikasikan pada tipe sungai perennial (Fleig 2004, Fleig et al. 2006). Secara umum, ambang batas $Q_{70}$ sampai $Q_{95}$ digunakan sebagai kriteria untuk analisis tipe sungai perennial (Fleig et al. 2006, Hisdal et al. 2004). Dalam penelitian ini, ambang batas yang digunakan adalah $Q_{80}$, yaitu aliran melampaui 80 persen dari panjang data (Gambar 4). Merujuk pada Van Loon dan Van Lanen (2012), $Q_{80}$ digunakan karena apabila menggunakan $Q_{95}$ maka kekeringan hidrologi yang teridentifikasi akan sedikit, sebaliknya akan banyak kekeringan yang teridentifikasi apabila menggunakan $Q_{70}$. Oleh karena itu dipilih nilai diantara $Q_{70^{-}} Q_{95}$ yaitu $Q_{80}$.

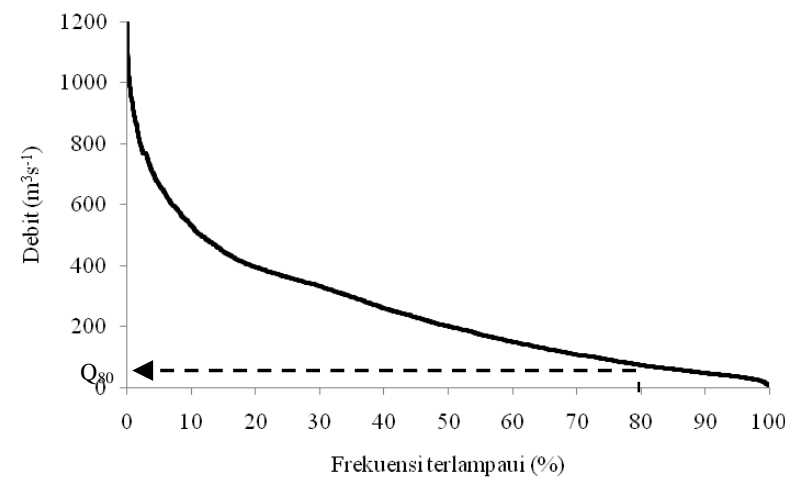

Gambar 1. Penentuan ambang batas $Q_{80}$ kurva durasi aliran

\section{Penentuan Durasi dan Volume Defisit Kekeringan Hidrologi}

Karakteristik kekeringan diperlukan untuk mengidentifikasi kekeringan hidrologi di suatu wilayah yaitu dengan menentukan waktu kejadian, awal dan akhir musim, durasi $\left(d_{i}\right)$, tingkat keparahan/ volume defisit $\left(v_{i}\right)$, dan aliran minimum $\left(Q_{\min }\right)$ pada suatu kejadian kekeringan hidrologi (Gambar 7, Fleig 2004, Hisdal et al. 2004). Cara menentukan durasi dan volume defisit kekeringan hidrologi yaitu dengan mengidentifikasi debit harian yang berada di bawah ambang batas $Q_{80}$. Ketika debit turun mencapai ambang batas maka kekeringan di mulai (onset date) dan apabila aliran naik mencapai ambang batas maka kejadian 
kekeringan berakhir (termination date). Durasi adalah panjang hari dari tanggal awal sampai tanggal akhir kekeringan. Akumulasi selisih antara ambang batas dan debit di bawah ambang batas sepanjang durasi kekeringan dalam satuan volume disebut volume defisit $\left(\mathrm{m}^{3}\right)$.

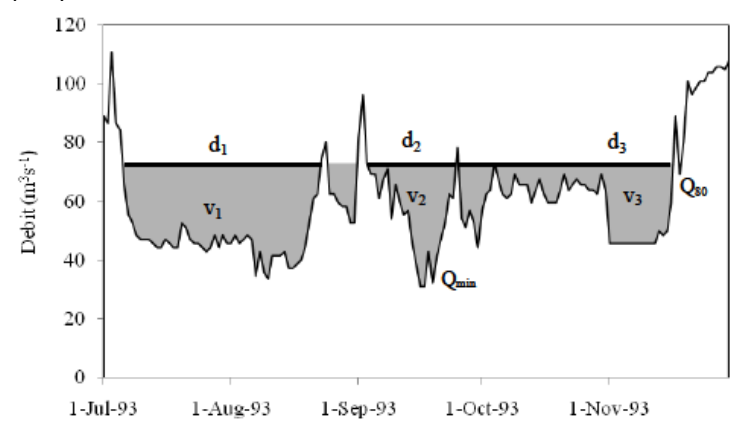

Gambar 2. Definisi karakteristik kekeringan hidrologi

Apabila terdapat kekeringan minor dalam proses identifikasi, maka kekeringan minor tersebut harus dihilangkan agar tidak mengganggu dalam proses analisis. Kekeringan minor (minor drought) merupakan peristiwa kekeringan dengan durasi yang pendek dan volume defisit yang kecil (Fleig et al. 2006). Salah satu cara yang dapat dilakukan untuk menghilangkan kekeringan minor yaitu menggunakan durasi minimum kekeringan $d_{\text {min }}$ 10 hari (Kaznowska dan Banasik 2011). Beberapa penelitian menggunakan $d_{\min } 5$ hari untuk $Q_{90}$ (Fleig et al. 2006, Hisdal et al. 2004) karena semakin tinggi ambang batas maka hari di bawah ambang batas semakin sedikit. Data yang dihasilkan dari identifikasi karakteristik kekeringan berupa data partial duration series (PDS), yaitu semua data yang berada di bawah ambang batas.

Karakteristik kekeringan digunakan untuk menduga tingkat keparahan antara lain:

$$
\begin{aligned}
d_{a v, n} & =\Sigma d_{n i} / \sum n_{i} \\
v_{a v, n} & =\Sigma v_{n i} / \Sigma n_{i} \\
\lambda & =\Sigma n_{i} / N
\end{aligned}
$$

$d_{a v, n}$ adalah rata-rata durasi kekeringan pada periode tertentu (hari), $d_{n i}$ jumlah hari seluruh kekeringan yang teridentifikasi pada periode kajian (hari), $n_{i}$ jumlah kekeringan hidrologi yang teridentifikasi Rata-rata volume defisit $\left(\mathrm{m}^{3}\right)$ ditunjukan dengan $v_{a v, n}, v_{n i}$ jumlah volume kekeringan yang teridentifikasi $\left(\mathrm{m}^{3}\right), N$ merupakan jumlah tahun pada periode kajian, dan $\lambda$ merupakan intensitas jumlah kejadian kekeringan hidrologi di DAS tersebut (Kaznowska 2011, Kaznowska dan Banasik 2011, Tallaksen et al. 2004).

\section{Analisis Frekuensi}

Analisis frekuensi digunakan untuk mengetahui peluang suatu kejadian kekeringan atau mengetahui frekuensi kejadian pada waktu lampau maupun masa depan (Haan 1977). Sampel data yang digunakan dalam analisis frekuensi adalah data PDS dari durasi dan volume defisit kekeringan di masing-masing DAS. Menurut Haan (1977), data yang digunakan dalam analisis frekuensi harus bersifat homogen dan independen agar dapat merepresentasikan suatu kejadian dari waktu ke waktu.

Analisis frekuensi pada penelitian ini berfokus pada dua karakteristik kekeringan yaitu durasi dan volume defisit. Peluang suatu kejadian kekeringan dapat dilihat dengan menghitung periode ulang (return period). Periode ulang $T(x)$ merupakan interval waktu rata-rata antara kekeringan yang satu dengan yang lain dengan besaran (magnitude) lebih besar dari nilai magnitude tertentu $(x)$. Kejadian kekeringan dengan besaran tertentu melampaui nilai $x$ akan terjadi sekali dalam $T$ tahun (Fleig 2004). Periode ulang untuk PDS dapat dihitung menggunakan persamaan (Tallaksen et al. 2004):

$$
T(x)=1 /\left(\lambda\left(i /\left(n_{i}+1\right)\right)\right)
$$

$T(x)$ merupakan periode ulang, $\lambda$ intensitas kejadian kekeringan per tahun, $i$ rank, $n_{i} \quad$ jumlah kekeringan dalam periode waktu tertentu.

\section{HASIL PENELITIAN \\ Karakteristik Kekeringan}

Dari perhitungan data debit periode tahun 1918-1935 dan 1973-2010 menggunakan metode flow duration curve, diperoleh nilai ambang batas aliran DAS Citarum Hulu sebesar $14,6 \mathrm{~m}^{3} \mathrm{~s}^{-1}$. Nilai ambang batas ini menjadi indikator dalam menentukan karakteristik kekeringan hidrologi di DAS Citarum Hulu. Ketika debit turun melampau ambang batas, maka kekeringan hidrologi di mulai dan berakhir ketika debit sudah naik melampaui ambang batasnya. Hasil identifikasi menunjukan bahwa terdapat 106 kali teridentifikasi kekeringan dari periode data yang tersedia atau terdapat dua periode kejadian kekeringan dalam setahun. 

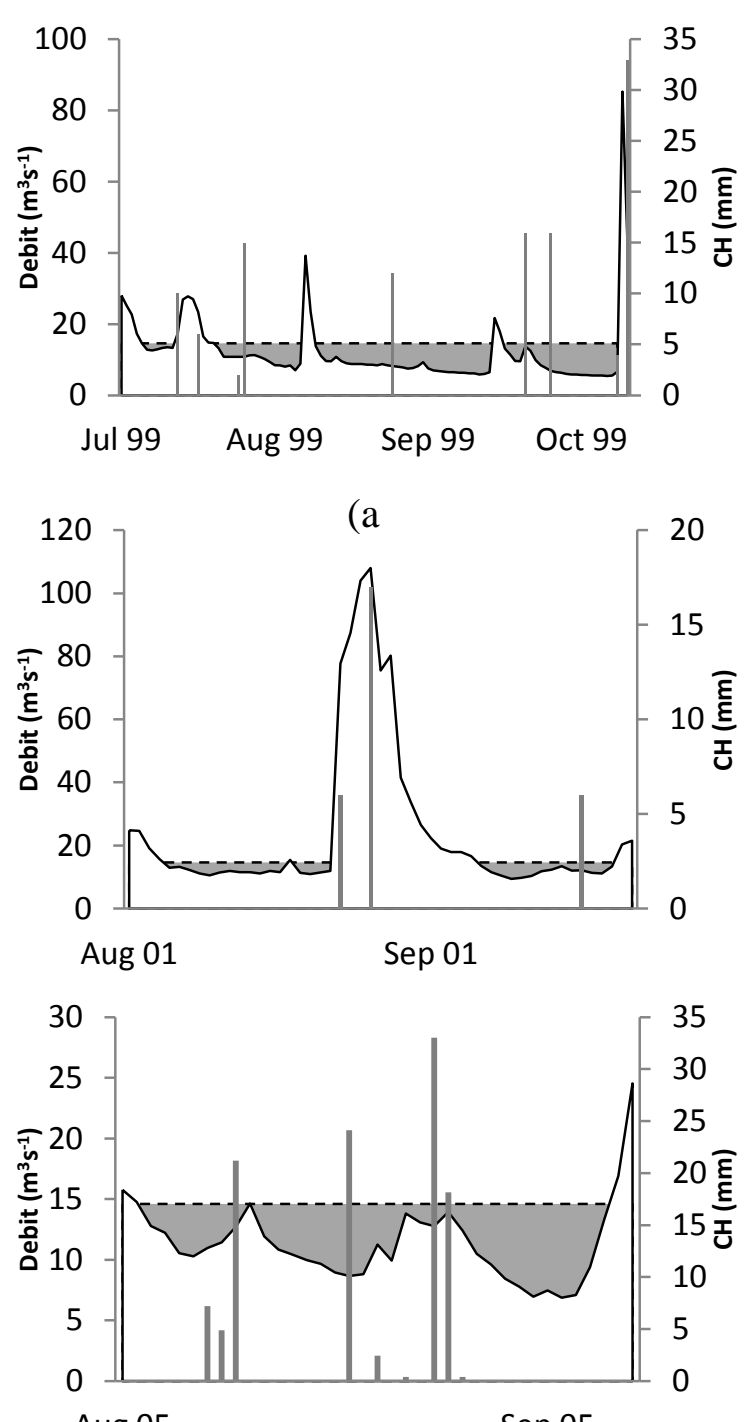

Aug 05

Sep 05

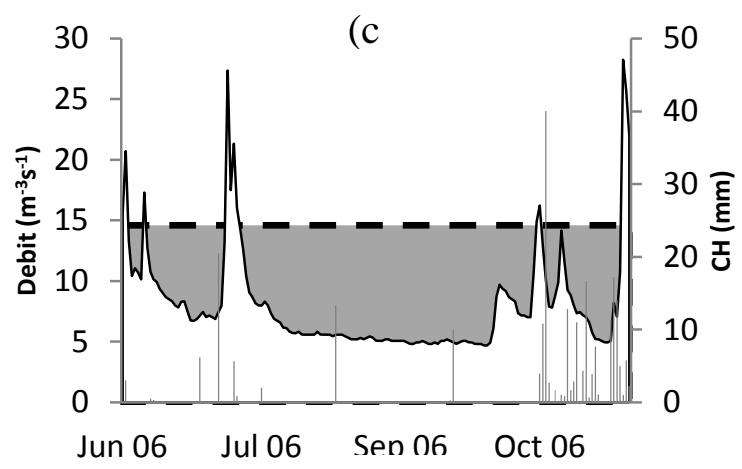

(d)
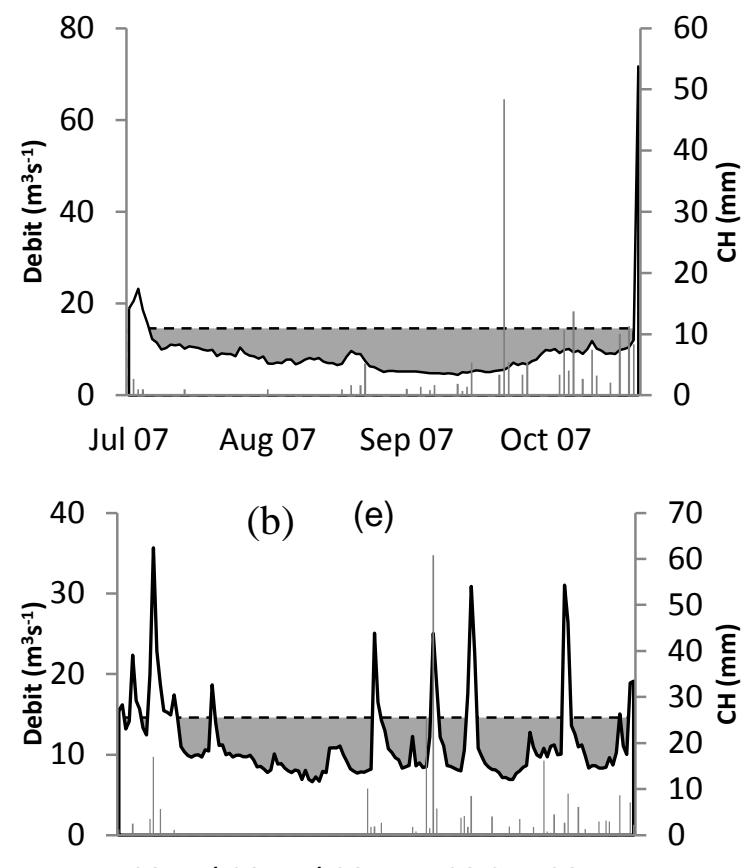

Jun 08 Jul 08 Jul 08 Aug 08 Sep 08

(f)

Gambar 3. Grafik hubungan antara karakteristik kekeringan hidrologi di dengan curah hujan di DAS Citarum Hulu, (a) kekeringan pada tahun 1999, (b) 2001, (c) 2005, (d) 2006, (e) 2007, dan (f) 2008

Kejadian kekeringan hidrologi terparah terjadi pada tahun 1994 dimana kekeringan terparah terjadi selama 111 hari dengan defisit volume sebesar $78,815 \times 10^{6} \mathrm{~m}^{3}$ terdapat dua periode kekeringan lainnya di tahun yang sama dengan durasi 10 dan 11 hari. Karena masingmasing kekeringan masih saling ketergantungan maka biasanya kekeringan tersebut tetap disebut satu kejadian kekeringan. Zelenhasic dan Salvai (1987) memperkenalkan kriteria waktu antar kejadian kekeringan. Oleh karena itu ditetapkan durasi yang relatif sebentar yang memisahkan antar kejadian kekeringan disebut durasi kritis. Ketika durasi yang memisahkan antar kekeringan kurang dari durasi kritis, maka dua kekeringan yang terpisah oleh durasi kritis tersebut digabungkan menjadi satu kejadian kekeringan. Durasi kritis yang digunakan Zelenhasic dan Salvai (1987) adalah 6 hari. Jadi, kekeringan pada tahun 1994 dapat digabungkan dan durasi kekeringannya menjadi 134 hari dari 27 Juni - 14 November 1994 dan volume defisit sebesar $95.246 \times 10^{6} \mathrm{~m}^{3}$.

Data curah hujan digunakan untuk mengetahui hubungan antara curah hujan dengan karakteristik kekeringan hidrologi di DAS Citarum Hulu. Data curah wilayah yang digunakan dari tahun 1999 hingga 2008 merupakan data curah hujan dari 3 wilayah DAS Citarum Hulu yaitu dari pos penakar Cisomang, 
Cicalengka, dan Cisondari yang kemudian dirata-ratakan. Kemudian karakteristik kekeringan hidrologi yang teridetifikasi pada tahun 1999-2008 dianalisis relasinya dengan data curah hujan yang tersedia dan diperoleh 6 kejadian kekeringan yang teridentifikasi. Hasil tersebut dapat dilihat pada Gambar 3 hubungan antara kekeringan hidrologi dengan curah hujan. Pada gambar tersebut secara keseluruhan terlihat bahwa pola debit harian yang terukur kurang lebih mengikuti pola curah hujan harian, dengan sedikit pergeseran ke kanan oleh puncak-puncak debit.

Pada tanggal 11-16 Juli 1999 debit yang terukur mulai mengalami defisit atau nilainya kurang dari $Q_{80}$. Akan tetapi karena durasi kurang dari 10 hari, maka periode ini belum bisa dikatakan sebagai periode kekeringan. Setelah itu, adanya dua puncak curah hujan pada gambar 3(a) (17 Juli 1999 curah hujan 10 mm; 21 Juli 1999 curah hujan $6 \mathrm{~mm}$ ) sepertinya cukup untuk mengembalikan kondisi DAS dari defisit pada tanggal 11-16 Juli yang nilainya masih relatif kecil.

Seiring dengan berlalunya hari tanpa curah hujan, debit yang terukur kembali turun hingga mencapai kondisi kekeringan hidrologi pertama pada tahun 1999 yang dimulai dari tanggal 25 Juli hingga 10 Agustus 1999. Defisit yang terbentuk pun semakin besar dari hari ke hari karena tidak ada input curah hujan. Pada tanggal 30 Juli 1999 terjadi curah hujan $15 \mathrm{~mm}$. Akan tetapi, pengaruh hujan tersebut terhadap DAS sepertinya baru terlihat 12 hari kemudian yaitu pada tanggal 11 Agustus 1999 sebesar $39.2 \mathrm{~m}^{3} \mathrm{~s}^{-1}$ yang menyebabkan debit naik di atas ambang batas. Hal tersebut menunjukan bahwa terdapat keterlambatan pengaruh curah hujan terhadap debit.

Pada tanggal 13 Agustus hingga 16 September 1999, kekeringan hidrologi kembali terjadi dengan rata-rata volume defisit $19.627 \mathrm{x}$ $10^{6} \mathrm{~m}^{3}$. Hujan yang terjadi pada periode kekeringan tersebut yaitu pada tanggal 28 Agustus 1999 dengan curah hujan sebesar 12 $\mathrm{mm}$ baru terlihat pengaruhnya 20 hari setelahnya, yaitu pada tanggal 17 dan 18 September 1999 dengan debit sebesar 21.7 $\mathrm{m}^{3} \mathrm{~s}^{-1}$ dan $17.9 \mathrm{~m}^{3} \mathrm{~s}^{-1}$. Setelah itu, kekeringan hidrologi mulai terjadi lagi pada tanggal 19 September hingga 11 Oktober 1999 dengan total volume defisit $13.532 \times 10^{6} \mathrm{~m}^{3}$. Curah hujan pada tanggal 23 maupun 28 september 1999 masing-masing sebesar $16 \mathrm{~mm}$, pengaruhnya baru terlihat 13-18 hari setelahnya, yaitu pada tanggal 12 Oktober 1999 dan mampu menaikan debit sebesar $85.3 \mathrm{~m}^{3} \mathrm{~s}^{1}$. Setelah itu hingga akhir tahun, hujan mulai sering terjadi dengan intensitas yang cukup tinggi, sehingga kekeringan pada tahun 1999 tidak lagi terjadi.
Jika dilihat pada gambar 3 (a), kejadian kekeringan yang terjadi selama tahun 1999, seolah terpotong-potong dengan beberapa debit yang melampaui ambang batas karena input dari curah hujan yang kemudian debit turun kembali ke bawah ambang batas. Karena masingmasing kekeringan masih saling ketergantungan dan durasi antar kekeringan kurang dari durasi kritis (6 hari), maka kekeringan tersebut tetap disebut satu kejadian kekeringan. Oleh karena itu, tiga kejadian kekeringan yang terpisah-pisah di tahun 1999 merupakan satu kejadian kekeringan yang saling berpengaruh. Sehingga kekeringan pada tahun 1999 terjadi dari bulan Juli hingga Oktober 1999.

Terdapat dua periode kekeringan yang terjadi pada tahun 2001 yaitu dari tanggal 15-26 Agustus dan 15-28 September (gambar 3 (b)). Karena durasi antar kekeringan lebih besar dari durasi kritis yang ditentukan (6 hari) maka kedua kekeringan tersebut tidak bisa digabungkan menjadi satu kejadian kekeringan yang saling mempengaruhi. Dua kekeringan tersebut dipisahkan oleh satu puncak debit yang melampaui ambang batas. Karena volume defisit yang terjadi pada kekeringan pertama cukup rendah yaitu $2.97 \times 10^{6} \mathrm{~m}^{3}$, maka curah hujan sebesar $6 \mathrm{~mm}$ pada tanggal 1 September langsung mempengaruhi debit hingga $77.7 \mathrm{~m}^{3} \mathrm{~s}^{-1}$ dan kekeringan hidrologi pun berakhir.

Pada tahun 2005 kejadian kekeringan hidrologi yang teridentifikasi mulai dari tanggal 15 Agustus hingga 8 September atau selama 25 hari. Rata-rata curah hujan wilayah bulanan mulai rendah sebesar $83 \mathrm{~mm}$ pada bulan Juli kemudian naik lagi pada bulan Agustus sebesar $136 \mathrm{~mm}$. Debit paling rendah terdeteksi pada tanggal 5 September sebesar $6.87 \mathrm{~m}^{3} \mathrm{~s}^{-1}$. Dari gambar 3 (c) dapat dilihat bahwa beberapa kali curah hujan mempengaruhi debit selama periode kekeringan namun debit belum melampaui ambang batas. Hal tersebut karena curah hujan pada tahun tersebut banyak hari tanpa hujan, sehingga ketika ada hujan, debit akan mudah turun kembali.

Selama periode tahun 1999-2008, kekeringan yang terjadi pada tahun 2006 merupakan kejadian yang paling parah dengan total volume defisit $98.5 \times 10^{6} \mathrm{~m}^{3}$. Debit mulai turun di bawah ambang batas sejak tanggal 24 Juni-24 November, berarti hampir setengah tahun debit berada di bawah normal (gambar 3 (d)). Selama kekeringan tersebut, terdapat satu puncak debit di atas ambang batas yang cukup tinggi sebesar $27.4 \mathrm{~m}^{3} \mathrm{~s}^{-1}$ memisahkan kekeringan karena ada input dari curah hujan sebesar $20.5 \mathrm{~mm}$. Dari grafik terlihat bahwa curah hujan tersebut tidak langsung mempengaruhi debit tetapi ada keterlambatan (lag) selama 5 hari. 
Kejadian kekeringan pada tahun 2007 terjadi selama 105 hari dari bulan Juli sampai Oktober tanpa adanya durasi kritis antar kejadian seperti kekeringan pada tahun-tahun sebelumnya. Dari gambar 3 (e) dapat dilihat bahwa terdapat satu kejadian ekstrem hujan di antara kekeringan. Perlu waktu sekitar sebulan agar air hujan tersebut dapat mengisi sungai karena kondisi sebelumnya debit sangat rendah mencapai $4.4 \mathrm{~m}^{3} \mathrm{~s}^{-1}$ dan hanya mendapat input hujan yang sedikit. Tingkat keparahan/volume defisit kekeringan yang terjadi pada tahun ini sebesar $61.047 \times 10^{6} \mathrm{~m}^{3}$. Berbeda dari kejadian kekeringan tahun 2007, kejadian kekeringan tahun 2008 yang memiliki banyak durasi kritis yang memisahkan antar kekeringan (gambar 3 (f)). Hal tersebut karena ada input curah hujan dan cenderung tersebar merata dan lebih sedikit hari tanpa hujan sepanjang bulan Agustung hingga Oktober 2008.

Pada tahun 2000, debit yang berada di bawah ambang batas tidak termasuk dalam kekeringan karena durasi yang kurang dari 10 hari. Namun, jika dilihat dari akumulasi curah hujan tahunannya cendering lebih rendah dari tahun-tahun yang lainnya. Hal tersebut terjadi karena curah hujan pada tahun 2000 tersebut lebih tersebar merata dari segi waktu dibandingkan curah hujan pada tahun 1999 dan 2001. Selain itu, jumlah hari tanpa hujan pada tahun 2000 juga lebih sedikit dibandingkan pada tahun 1999.

\section{Analisis Frekuensi}

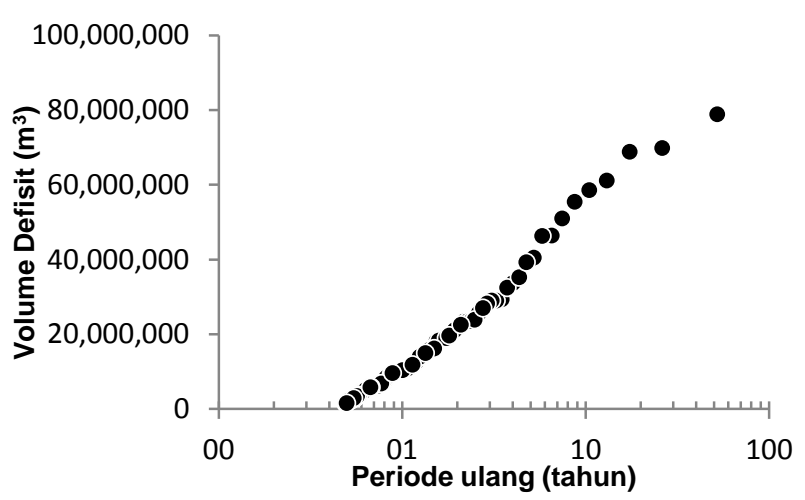

Gambar 4. Periode ulang berdasarkan tingkat keparahan kekeringan

Penting untuk mengetahui seberapa lama periode ulang suatu kejadian kekeringan berdasarkan tingkat keparahannya. DAS Citarum Hulu memiliki kejadian kekeringan hidrologi volume defisit maksimum pada tahun 1994 dan durasi maksimum pada tahun 1997. Periode ulang kejadian kekeringan dengan volume defisit maksimum mencapai 52 tahun dari periode data yang tersedia (Gambar 4), atau dari panjang periode tahun yang tersedia hanya berpeluang terjadi satu kali kejadian dengan volume defisit setara atau melampaui $78.815 \mathrm{x}$
$10^{6} \mathrm{~m}^{3}$. Kejadian dengan periode ulang 26 tahun atau peluang terjadi dua kali selama periode kajian terjadi jika nilai volume defisit setara atau melampaui $69.760 \times 10^{6} \mathrm{~m}^{3}$.

Tabel 1. Frekuensi durasi kekeringan di DAS Citarum Hulu

\begin{tabular}{lll}
\hline $\begin{array}{l}\text { Durasi } \\
\text { (hari) }\end{array}$ & $\begin{array}{l}\text { Jumlah } \\
\text { Kekeringan }\end{array}$ & $\begin{array}{l}\text { Persentase } \\
(\%)\end{array}$ \\
\hline \hline $10-20$ & 58 & 55 \\
$21-50$ & 36 & 34 \\
$51-100$ & 9 & 8 \\
$>100$ & 3 & 3 \\
\hline \hline Jumlah & 106 & 100 \\
\hline
\end{tabular}

Lebih dari setengah kejadian kekeringan yang teridentifikasi di DAS Citarum Hulu memiliki durasi kurang dari 20 hari. Hal tersebut menunjukan bahwa kekeringan dengan durasi pendek memiliki peluang yang besar untuk terjadi. Sepertiga kekeringan hidrologi yang teridentifikasi memiliki durasi kekeringan antara 21 hingga 50 hari, sedangkan kekeringan dengan durasi lebih dari 100 hari memiliki peluang terjadi paling tidak tiga kali dalam periode 100 tahun.

\section{KESIMPULAN}

Identifikasi karakteristik kekeringan hidrologi di DAS Citarum Hulu sangat penting terutama untuk mengetahui input debit untuk waduk Saguling. Kekeringan hidrologi di subdas ini rata-rata terjadi pada bulan Juni hingga Oktober, bahkan bisa terjadi hingga bulan November jika kekeringan tersebut parah seperti pada tahun 2006. Kekeringan-keringan tersebut umumnya diawali dengan masa banyaknya hari tanpa hujan pada bulan sebelumnya yang kemudian akan mempengaruhi debit secara perlahan hingga debit berada di bawah ambang batas kekeringan sebesar $14.6 \mathrm{~m}^{3} \mathrm{~s}^{-1}$. Beberapa kejadian memiliki durasi kritis karena input dari curah hujan cukup tinggi dan terdapat beberapa kejadian hujan pada periode kekeringan. Respon curah hujan terhadap debit bisa berbeda-beda tergantung kondisi defisit ketika kekeringan terjadi. Semakin besar defisitnya, maka curah hujan semakin lambat mempengaruhi debit. Dari hasil analisis frekuensi kejadian, kekeringan maksimum pada tahun 1994 dengan volume defisit $78.815 \times 10^{6}$ $\mathrm{m}^{3}$ memiliki perode ulang 52 tahun dan lebih dari separuh kekeringan yang teridentifikasi memiliki durasi kurang dari 20 hari.

\section{DAFTAR PUSTAKA}

Cahyaningsih A dan Harsoyo B. 2010. Distribusi spasial tingkat pencemaran air di DAS 
Citarum. Jurnal Sains dan Teknologi Modifikasi Cuaca. 11(2): 1-9.

Fleig A. 2004. Hydrological drought -A comparative study using daily discharge series from around the world [disertasi]. Freiburg (DE): Univesitas Albert-Ludwigs.

Fleig AK, Tallaksen LM, Hisdal H, Demunth S. 2006. A global evaluation of streamflow drought characteristics. Hydrol. Earth Syst. Sci. 10:535:552.

Haan CT. 1977. Statistical Method in Hydrology. Ames (US): The lowa State University Press.

Hisdal H, Tallaksen LM, Clausen B, Peters E, Gustard A. 2004. Hydrological drought characteristics. Di dalam: Tallaksen LM, Van Lanen HAJ, editor. Hydrological Drought: Processes and Estimation Methods for Streamflow and Groundwater. Volume 48. Development Water in Science. Amsterdam (NL): Elsevier. hlm 139-198.

Kaznowska E. 2011. Analysis of low flow characteristics and drought frequency in agricultural catchments. $\mathrm{Di}$ dalam: Banasik K, Øygarden L, Hejduk L, editor. Prediction and Reduction of Diffuse Pollution, Solid Emission and Extreme Flows from Rural Areas - case study of small agricultural catchment. Warsawa (PL): SGGW. hlm 27-46.

Kaznowska E, Banasik K. 2011. Streamflow droughts and probability of their occurance in a small agricultural catchment. Land Reclamation 43(1):5769.

Marganingrum D, Arwin, Roosmini D, dan Pradono. 2013. Dampak variabilitas hujan dan konversi lahan terhadap sensitifitas debit aliran sungai citarum. Forum Geografi. 27(1): 11-22.

Searcy JK. 1969. Flow Duration Curves, Manual of Hydrology: Part 2 Low Flow Techniques. Washington (US): US Government Printing Office.

Tallaksen LM, Madsen H, Hisdal H. 2004. Frequency analysis. Di dalam: Tallaksen LM, Van Lanen HAJ, editor. Hydrological Drought: Processes and Estimation Methods for Streamflow and Groundwater. Volume 48. Development Water in Science. Amsterdam (NL): Elsevier. hlm 199-271.

Tallaksen LM dan Van Lanen. 2004. Introduction. Tallaksen LM, Van Lanen HAJ, editor Hydrological Drought: Processes and Estimation Methods for Streamflow and Groundwater. Volume 48. Development Water in Science. Amsterdam (NL): Elsevier. hlm 3-17.
Van Loon AF dan Van Lanen HAJ. 2012. A process-based typology of hydrological drought. Hydrol. Earth Syst. Sci. 16:19151946.

[WMO] World Meteorological Organization. 2008. Manual on Low Flow and Estimation. WMO No. 1029.

Zelenhasić, E. dan A. Salvai. 1987. A Method of Streamflow Drought Analysis. Water Resources Research, 23(1), 156-168.

Zelenhasic E. 2002. On the extreme streamflow drought analysis. Water Resource Management 16:105-132. 
